\title{
Efeito do procedimento de mistura no comportamento no estado fresco de argamassas de revestimento produzida em obra e industrializada
}

\author{
The influence of mixing procedure on fresh \\ behavior of industrialized coating mortar \\ and on site produced mortar
}

\author{
Eiji Fukui ${ }^{1}$, Eliziane Jubanski Martins ${ }^{2}$, Heloisa Fuganti Campos ${ }^{3}$, Maria Clara Cavalini Pinto ${ }^{4}$, Sarah \\ Honorato Lopes da Silva ${ }^{5}$, Thaísa Mariana Santiago Rocha ${ }^{6}$, Vitor Lorival Kudlanvec Junior ${ }^{7}$, \\ Marienne do Rocio de Mello Maron da $\operatorname{Costa}^{8}$
}

\footnotetext{
${ }^{1}$ Votorantim Cimentos - Centro de Pesquisa e Desenvolvimento, Curitiba, PR, Brasil e-mail: eiji.fukui@vcimentos.com

2, 3,4,5,6,7,8 Universidade Federal do Paraná, Curitiba, PR, Brasil

e-mail: elizianej@hotmail.com, helo_camposs@hotmail.com, mclaracavalini@gmail.com, sarahhlds@gmail.com, thaisamsrocha@yahoo.com.br, vitorlorival86@gmail.com,mariennemaron@gmail.com
}

\begin{abstract}
RESUMO
A sequência com a qual os materiais são adicionados à mistura influenciam diretamente o comportamento de argamassas no estado fresco e irá refletir na qualidade do revestimento. Sendo assim, este artigo propõe a análise de como diferentes tipos de procedimento de mistura interferem no comportamento no estado fresco de dois tipos distintos de argamassas, sendo elas argamassa de revestimento industrializada (AI) e argamassa produzida em obra (APO). Na pesquisa, foram adotados quatro tipos de mistura para analisar o comportamento das argamassas, sendo elas mistura manual com água livre (MAL), mistura mecânica do tipo pó na água (PA), mistura mecânica do tipo água no pó (AP) e mistura manual com água fixa (MAF). As argamassas foram submetidas aos ensaios de determinação da densidade a fresco e teor de ar aprisionado e, também, caracterizadas reologicamente pelo método do Squeeze-flow. Esta última análise foi efetuada em tempo zero após mistura (T0) e 20 minutos após mistura (T20). Os resultados indicaram a presença de aditivo incorporador de ar na argamassa industrializada, uma vez que esse tipo de argamassa apresentou alto teor de ar quando comparada à argamassa produzida em obra. Por outro lado, as misturas produzidas manualmente apresentaram menor aprisionamento de ar quando comparadas com o procedimento mecânico em argamassadeira. O procedimento de mistura teve uma influência expressiva no desempenho da argamassa industrializada, provavelmente devido à presença de aditivo incorporador de ar. As argamassas produzidas em obra, que não possuíam aditivos, apresentaram desempenhos semelhantes para ambos os métodos de mistura.
\end{abstract}

Palavras-chave: procedimento de mistura, reologia, argamassas de revestimento, Squeeze-flow.

\section{ABSTRACT}

The sequence with which materials are added to the mixtures influences the behavior of fresh mortars and will reflect on the quality of the coating. Therefore, the aim of this article is to analyse how different types of mixtures procedures interfere on the fresh behavior of two different types of mortar - industrialized coating mortar (AI) and mortar produced on site (APO). In this research, the four types of mortar mixtures adopted to analyze the mortar behavior were: manual mixing with free water (MAL), powder on water mechanical mixture (PA), water on powder mechanical mixture (AP) and manual mixture with fixed water (MAF). The mortars were submitted to tests for the determination of fresh density and trapped air content and also characterized rheologicaly by the Squeeze-flow method. This last analysis was performed at time zero after mixing (T0) and 20 minutes after mixing (T20). After mixtures the mortars were tested for fresh density, incorporated air content and rheological behavior by Squeeze-flow method. This last test was made immediately after mixture (T0) and twenty minutes after mixture (T20). The results indicated the presence of an additive incorporating air in the industrialized mortar, since this type of mortar presented high air content 
when compared to the mortar produced on site. In contrast, the mixtures produced by hand presented less air entrapment when compared to the mechanical procedure in the mortar. The mixing procedure had a significant influence on the performance of the industrialized mortar, probably due to the presence of the air entraining additive. Mortars produced on site, which had no additives, showed similar performances for both mixing methods.

Keywords: mixture procedure, rheology, coating mortar, Squeeze-flow.

\section{INTRODUÇÃO}

As argamassas industrializadas são produzidas por processos com controles rígidos, e, por isso, geralmente apresentam uniformidade da dosagem, ou seja, há o controle nas dosagens de cimento, areia, aditivos e adições [1]. De um modo geral essas argamassas apresentam aditivos incorporadores de ar e retentores de água, que são adicionados na mistura para agir durante o tempo de aplicação da argamassa, proporcionando trabalhabilidade e evitando a exsudação na etapa de execução do revestimento. Já as argamassas produzidas em obra não possuem controle, sendo comum a dosagem da areia em volume causando diferenças muitas vezes expressivas do teor desse insumo na mistura [2]. Ambos os tipos de argamassas sofrem influências do processo de mistura adotado, o que poderá resultar em aprisionamento de ar mistura.

O procedimento de mistura das argamassas de revestimento, ou seja, a sequência de adição dos insumos na mistura é fundamental para o desempenho no estado fresco. Nesse procedimento deve existir uma garantia de homogeneidade, a padronização do traço e o controle do consumo de água, que são fatores que deverão influenciar diretamente na obtenção de bons resultados [3].

Segundo ANTUNES et al. [4], a escolha da forma de mistura, depende da natureza dos componentes a serem misturados. Numa mistura ideal, a pasta de cimento (ou a própria argamassa) deve estar isenta de aglomerados e todas as partículas envoltas em água fazendo com que a mistura tenha tendência a exibir baixa viscosidade facilitando sua utilização.

Uma pasta homogênea, por exemplo, pode ser obtida por um processo que forneça tensão suficiente para quebrar os aglomerados. Logo, é possível entender a afirmação de ANTUNES et al. [4] que relatam as propriedades das argamassas para os revestimentos como relacionadas à sua forma de mistura, ou seja, a sequência de mistura e a ordem em que cada insumo é adicionado são dados importantes a serem considerados.

Nos canteiros de obras, as argamassas geralmente são misturadas de duas formas: manual ou mecânica.

Dificilmente uma mistura manual conseguirá atingir o mesmo nível de desaglomeração e teor de ar aprisionado quando comparada ao procedimento mecânico e, por esse motivo, a NBR 7200 [5] preconiza a utilização de mistura por processo mecanizado e, somente em casos excepcionais, por processo manual. $\mathrm{O}$ processo manual tende a apresentar uma menor eficiência provocando a diminuição da produtividade da aplicação do revestimento. A mecanização no processo de mistura desses materiais, representa um avanço na tecnologia das argamassas de revestimento [6]. Além do procedimento de mistura, a NBR 7200 [5] salienta a necessidade das diversas argamassas produzidas no decorrer da obra de manterem a mesma trabalhabilidade e, para isso, se faz necessário corrigir teores de agregados e adições das misturas quando há variação de umidade.

Existem diversos ensaios utilizados para a caracterização reológica dessas argamassas, porém com os avanços na tecnologia das argamassas e concretos, ensaios com maior precisão vêm sendo aprimorados, principalmente com relação às características reológicas desses materiais $[7,8,9,10]$. O "Squeeze-flow", ou escoamento por compressão axial, normatizado pela NBR 15.839 [11] é utilizado para verificar e avaliar as propriedades reológicas dos materiais. Esse método consiste em mensurar o esforço necessário para comprimir uma suspensão entre duas placas paralelas. O princípio fundamental deste método é baseado no fato de que a deformação efetiva do material comprimido entre as placas ocorre por cisalhamento radial quando a razão entre o diâmetro e a espessura da amostra for elevada (D/h > 5). Razões inferiores levam ao surgimento de tensões de compressão [12].

Os resultados apresentados pelo ensaio de Squeeze-flow podem ser demonstrados na forma de um gráfico de carga $(\mathrm{N})$ versus deslocamento $(\mathrm{mm})$, sendo que este apresenta uma curva com três regiões bem distintas, conforme apresentado na Figura 1. O estágio I trata-se de um pequeno deslocamento que mostra a deformação elástica do material, o estágio II representa um deslocamento intermediário mostrando a deformação plástica ou fluxo viscoso e o estágio III se refere a um grande deslocamento e enrijecimento por deformação, influenciado pela aproximação dos agregados e o atrito formado pelos mesmos [13]. 


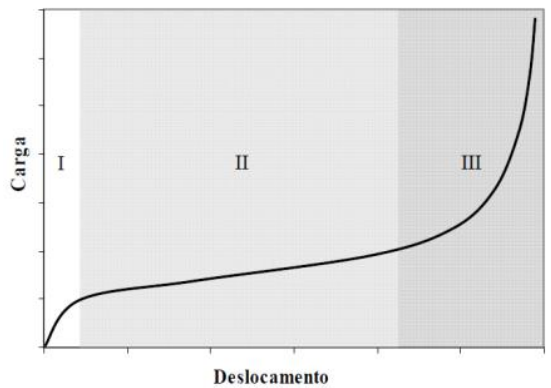

Figura 1: Modelo do perfil típico de carga versus deslocamento do ensaio de Squeeze-flow [13].

Esse método também pode ser empregado em outras áreas do conhecimento, como engenharia de alimentos e tecnologia de polímeros. Sua aplicação em argamassas apresenta resultados mais significativos em comparação ao ensaio de consistência, que também mede a deformação da argamassa, porém não possibilita distinguir entre a contribuição da tensão de escoamento e da viscosidade, como verificado no ensaio com Squeeze-flow.

O ensaio baseado no método de Squeeze-flow é simples de ser executado e de baixo custo, uma vez que utiliza máquinas universais de ensaio encontradas na maioria dos laboratórios de tecnologia de materiais $[13,14,15,16]$.

Para mais, vale salientar que o comportamento reológico das argamassas também é condicionado pela granulometria e forma das partículas que as compõem. Sendo assim, com relação à influência da granulometria no comportamento reológico dos materiais, há o grau de empacotamento das partículas onde a correta seleção da proporção e do tamanho adequado dos materiais particulados promove o preenchimento dos vazios maiores por partículas menores $[17,18]$; que por sua vez melhora a trabalhabilidade pelo efeito de rolagem entre as partículas. Ou seja, as partículas menores promovem a rolagem entre as maiores, melhorando a trabalhabilidade. Quanto à forma dos grãos, os mais lamelares tendem a reduzir a trabalhabilidade por dificultar a rolagem entre grãos, enquanto que grãos mais arredondados facilitariam.

Desta forma, esse trabalho tem como objetivo avaliar o impacto de diferentes tipos de procedimentos de mistura em duas argamassas distintas - argamassa de revestimento industrializada e argamassa produzida em obra - e os efeitos no comportamento reológico das mesmas utilizando, entre outras análises, o ensaio de Squeeze-flow.

\section{MATERIAIS E MÉTODOS}

Foram selecionados dois tipos de argamassas para a realização do estudo: uma argamassa de revestimento industrializada (AI) adquirida no mercado e uma argamassa produzida em obra (APO). A argamassa produzida em obra é constituída de cimento, cal e areia na proporção em volume 1:2:6, dosagem usada na obra onde foi coletada. Esta argamassa foi recebida para ensaio já com os materiais constituintes sólidos misturados. A dosagem da argamassa industrializada não foi fornecida pelo fabricante devido às questões de confidencialidade. Porém, a composição da argamassa apresentada na sacaria indica como constituintes: cimento Portland, agregados minerais artificiais com granulometria controlada e aditivos químicos. Dentre os aditivos normalmente presentes em argamassas industrializadas de revestimento, estão os aditivos incorporador de ar e retentor de água, que conferem ao material melhor trabalhabilidade, melhor coesão dos sistemas constituintes, redução da tendência de exsudação e melhor rendimento no estado fresco [19]. Para mais, as argamassas em estado anidro foram submetidas ao ensaio de granulometria, sendo que a frações maiores que $0,088 \mathrm{~mm}$ foram caracterizadas pelo granulômetro Camsizer, e as frações menores pelo granulômetro Malver.

As duas argamassas foram preparadas de quatro modos distintos visando-se avaliar a influência do procedimento de mistura no comportamento reológico. Foi adotada mistura manual e mistura mecânica em argamassadeira planetária com capacidade de 5 litros de laboratório, alterando-se também a sequência de adição de água na mistura anidra (água no pó e pó na água) e disponibilizando água livre na mistura manual de acordo com a percepção do operador quanto à trabalhabilidade da mistura.

\subsection{Mistura manual com água livre (MAL)}

O emprego da água livre da mistura manual foi efetuado com o intuito de simular as condições de dosagem de água praticadas em obra, de forma que nessa etapa prevaleceu o empirismo, em que o operador misturou a 
argamassa até obter a trabalhabilidade de aplicação que lhe parecia ideal. A quantidade de água foi determinada com o auxílio de um pedreiro com 26 anos de experiência em aplicações de emboço e reboco, para ambos os tipos de argamassa estudados.

\subsection{Mistura mecânica do tipo pó na água (PA)}

A mistura mecânica foi efetuada em misturador mecânico do tipo planetário com características conforme prescrito na NBR 7.215 [20]. O preparo da argamassa foi efetuado de acordo com a NBR 13.276, em que foi realizada mistura de $2,5 \mathrm{~kg}$ de material seco com a porção de água [21]. Para a argamassa industrializada, além dos 30 segundos, há um tempo adicional de 15 segundos, e para a mistura da argamassa APO o tempo adicional foi de 30 segundos, conforme determina a norma. A quantidade de água utilizada no preparo das argamassas foi determinada de duas maneiras distintas. Para a AI, a quantidade de água foi a mesma indicada pelo fabricante. Para a APO, determinou-se a quantidade de água através do teste da consistência na mesa vibratória em que a argamassa deve apresentar diâmetro médio de espalhamento de $260 \mathrm{~mm} \pm 10 \mathrm{~mm}$, conforme previsto na NBR 13.276 [21].

\subsection{Mistura mecânica do tipo água no pó (AP)}

Para a mistura mecânica do tipo água no pó (AP), apenas o procedimento de adição da água foi diferente do sugerido pela NBR 13.276 [21]. Optou-se por adicionar a água no pó e não o pó na água, a fim de verificar a influência da ordem de colocação dos materiais no estado fresco. O método consiste em introduzir $2,5 \mathrm{~kg}$ da argamassa anidra na cuba e com o misturador ligado na velocidade lenta, deve-se adicionar $75 \%$ da quantidade total de água em 10 segundos e continuar a mistura até 30 segundos. Em seguida, altera-se a velocidade do misturador para rápida e realiza-se a mistura do material por 60 segundos. Na sequência, desliga-se a argamassadeira e escarifica-se as laterais, o fundo do recipiente e a pá por 90 segundos. Por fim, deve-se acionar o misturador na velocidade lenta e adicionar os $25 \%$ restantes da água durante 10 segundos e misturar até 60 segundos nesta velocidade. A quantidade de água adotada para os dois tipos de argamassa foi a mesma utilizada para o método de mistura PA.

\subsection{Mistura manual com água fixa (MAF)}

Assim como para o método MAL, o mesmo operador realizou a mistura das argamassas manualmente. Porém, a quantidade de água adotada para as argamassas foi a mesma utilizada para os métodos de mistura PA e AP. Dessa forma, as argamassas apresentaram as seguintes relações água/materiais secos (Tabela 1):

Tabela 1: Identificação das argamassas e as respectivas relações água/materiais secos.

\begin{tabular}{c|c}
\hline $\begin{array}{c}\text { IDENTIFICAÇÃO } \\
\text { (MISTURA-ARGAMASSA) }\end{array}$ & $\begin{array}{c}\text { RELAÇÃO ÁGUA / } \\
\text { MATERIAIS SECOS }\end{array}$ \\
\hline MAL-APO & 0,15 \\
\hline MAL-AI & 0,17 \\
\hline PA-APO & 0,16 \\
\hline PA-AI & 0,16 \\
\hline AP-APO & 0,16 \\
\hline AP-AI & 0,16 \\
\hline MAF-APO & 0,16 \\
\hline MAF-AI & 0,16
\end{tabular}

A Figura 2 ilustra o fluxograma com as variáveis de estudo do presente trabalho. 


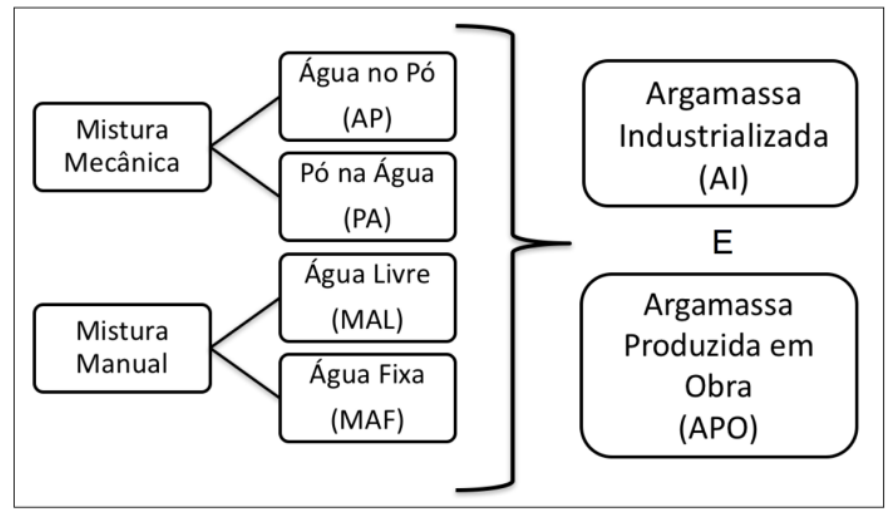

Figura 2: Variáveis de estudo (tipos de argamassa e de mistura).

Salienta-se que o procedimento de mistura previsto na NBR 13.276 [21] é direcionado para misturas em laboratório, e que o volume de argamassas produzidas influencia significativamente no comportamento desses materiais quanto à trabalhabilidade. Sendo assim, o presente trabalho visa analisar os métodos de mistura na trabalhabilidade para análises em laboratório, mas que para prática de obra seria necessária uma nova avaliação que contemple os equipamentos e o volume de mistura reais.

Após o procedimento de mistura das argamassas, as mesmas foram submetidas ao ensaio de determinação da densidade de massa fresca, sendo calculado também o teor de ar incorporado - NBR 13.278 [22], e caracterizado com relação ao seu comportamento reológico em triplicata pelo método do Squeeze-flow - NBR 15.839 [11]. Ressalta-se que no procedimento de ensaio da NBR 15.839 [11] está prescrito que a primeira leitura no Squeeze-flow deve ser realizada 15 minutos após o preparo da argamassa. No atual trabalho, a leitura foi efetuada em dois momentos distintos de moldagem: logo após o preparo da argamassa (T0) e 20 minutos após o preparo (T20). Ressalta-se que as argamassas moldadas em T20 permaneceram em repouso dentro da cuba de mistura até o momento da moldagem. Mesmo a norma prescrevendo uma leitura e que ela fosse feita 15 minutos após a mistura, nesse trabalho adotou-se dois tempos de leitura para que fosse possível avaliar a influência do tempo de repouso no comportamento no estado fresco da argamassa.

Ademais, explica-se que no presente trabalho foi necessário extrapolar o tempo de 15 para 20 minutos, a fim de assegurar que, no caso do tempo de repouso influenciar o comportamento da argamassa, que fosse possível observar as alterações provocadas pelo mesmo. Para cada tempo de leitura foram avaliados três corpos de prova. Sendo assim, dos resultados foram excluídas as curvas de Squeeze-flow espúrias, e para análise final foi feita uma curva média entre os resultados considerados.

\section{RESULTADOS E DISCUSSÕES}

Da análise granulométrica das argamassas percebe-se que a argamassa produzida em obra possui frações mais grossas em relação à industrializada (Figura 3). No entanto, esta apresenta uma descontinuidade granulométrica que foi identificada pela queda no pico de maior frequência. O maior teor de finos na argamassa industrializada é decorrente da origem do agregado miúdo da mesma. $\mathrm{O}$ agregado artificial, normalmente, é proveniente de processos de britagem que produzem materiais mais finos e de forma mais angular. Sendo assim, mesmo que a curva da AI apresente descontinuidade e os grãos sejam certamente mais angulares, essa argamassa deverá apresentar maior empacotamento das partículas pelo preenchimento dos vazios pelas partículas mais finas. 


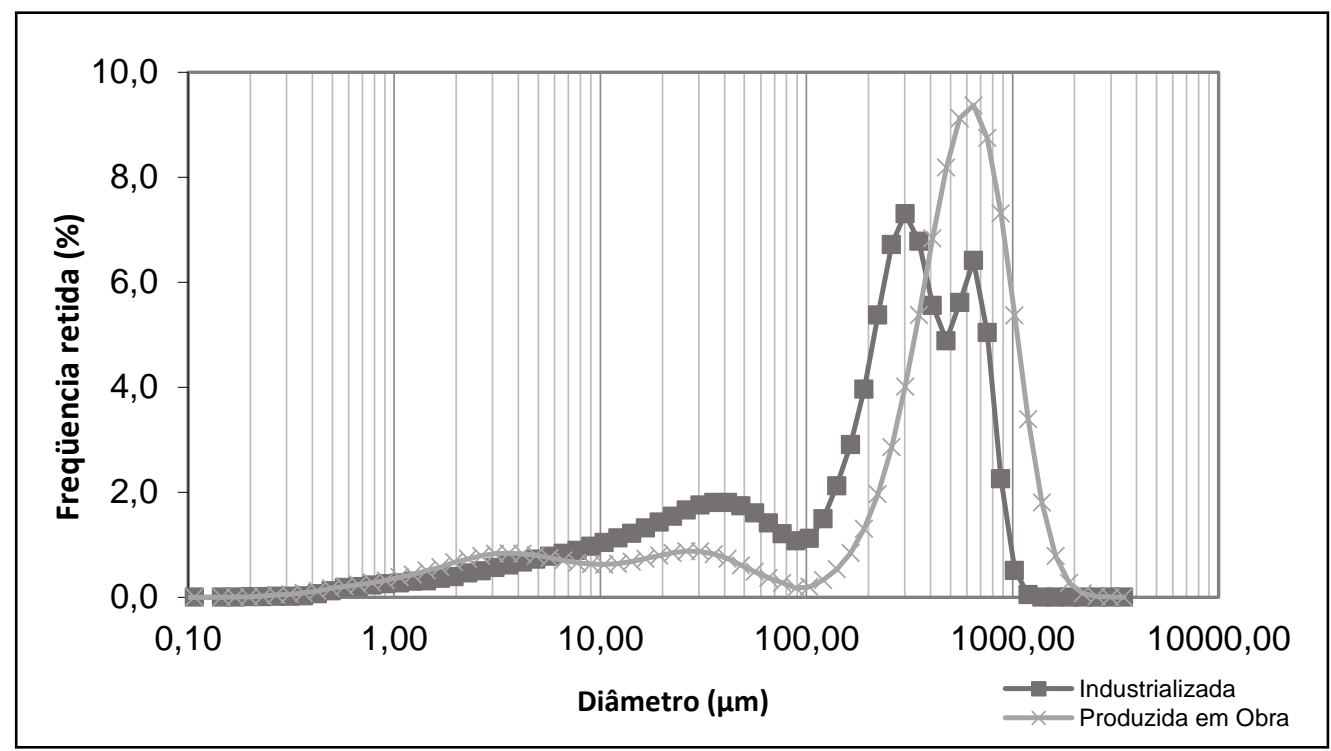

Figura 3: Curva granulométrica discreta das argamassas.

Os resultados dos ensaios no estado fresco das argamassas com diferentes procedimentos de mistura contemplam as seguintes análises para os dois tempos (T0 e T20), densidade no estado a fresco [22], teor de ar incorporado [22] e Squeeze-flow [10], os quais estão apresentados a seguir.

De acordo com SILVA [23] as argamassas trabalham em função da sua capacidade de fluir e de se deformar, quando submetida a uma determinada tensão de cisalhamento, apresentando um contato mais extenso com o substrato, otimizando o mecanismo de aderência. Uma argamassa deve apresentar um coeficiente de viscosidade plástica menor possível, para diminuir o seu adensamento e espalhamento e aumentar a tensão de escoamento, já que uma vez aplicada na parede não deve escorrer.

\subsection{Análise dos resultados de Densidade e Teor de Ar nas misturas frescas}

A partir dos dados obtidos (Figura 4), é possível afirmar que a argamassa produzida em obra (APO) apresenta densidade no estado fresco aproximadamente $10 \%$ maior que a argamassa industrializada (AI). Esses resultados foram obtidos em todos os processos de mistura, tal fato já era previsto, devido a composição da argamassa industrializada, que contêm aditivos químicos conforme descrição da composição contida na sacaria do produto.

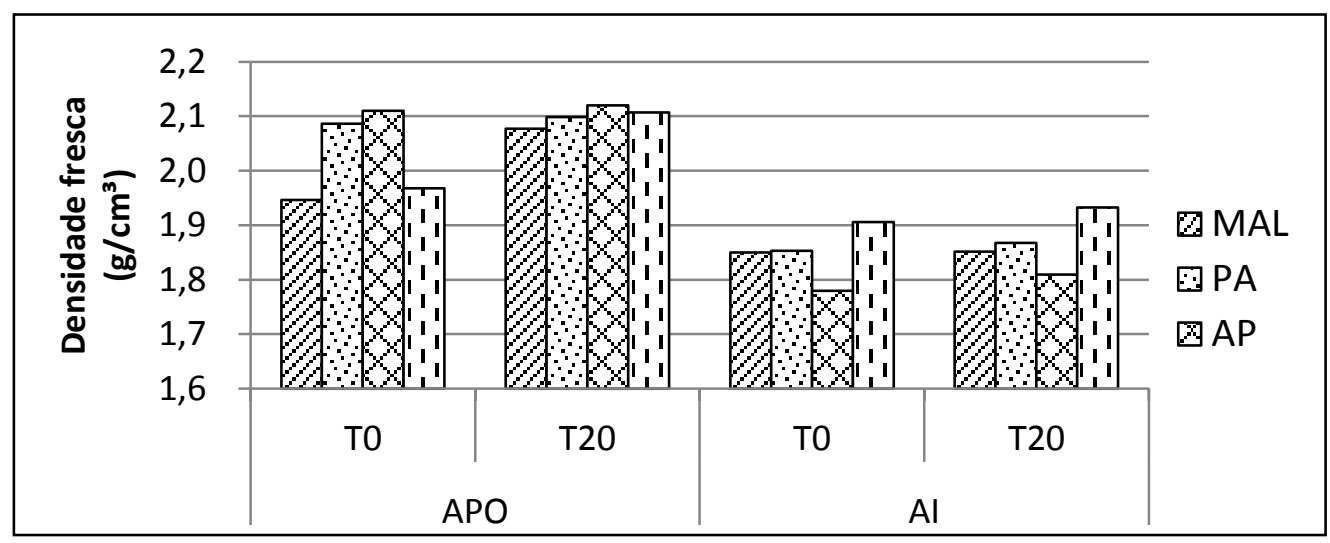

Figura 4: Resultados de densidade das argamassas no estado fresco.

Os aditivos incorporador de ar e o retentor de água utilizados nas argamassas industrializadas atuam através da criação de pequenas e promoção da estabilidade de bolhas uniformemente distribuídas na argamassa, respectivamente, levando a uma diminuição da densidade e um aumento da trabalhabilidade, afirmam SEABRA et al. [24]. A Figura 5 apresenta o comparativo do ar aprisionado na argamassa produzida em obra (já que essa formulação não continha aditivo incorporador de ar) com a industrializada; o teor de ar se 
mostrou, conforme esperado, inversamente proporcional à densidade de massa fresca da argamassa, ou seja, quanto menor a densidade maior o teor de ar. Segundo MATTANA et al. [25], considera-se que, quanto menor o valor da densidade de massa no estado fresco mais favorável, pois se economiza material e quanto maior o teor de ar, melhor a trabalhabilidade e menor a resistência mecânica. No entanto, ressalta-se que quanto à avaliação dos critérios técnicos, previstos da NBR 13.281 [26], isso não pode ser analisado.

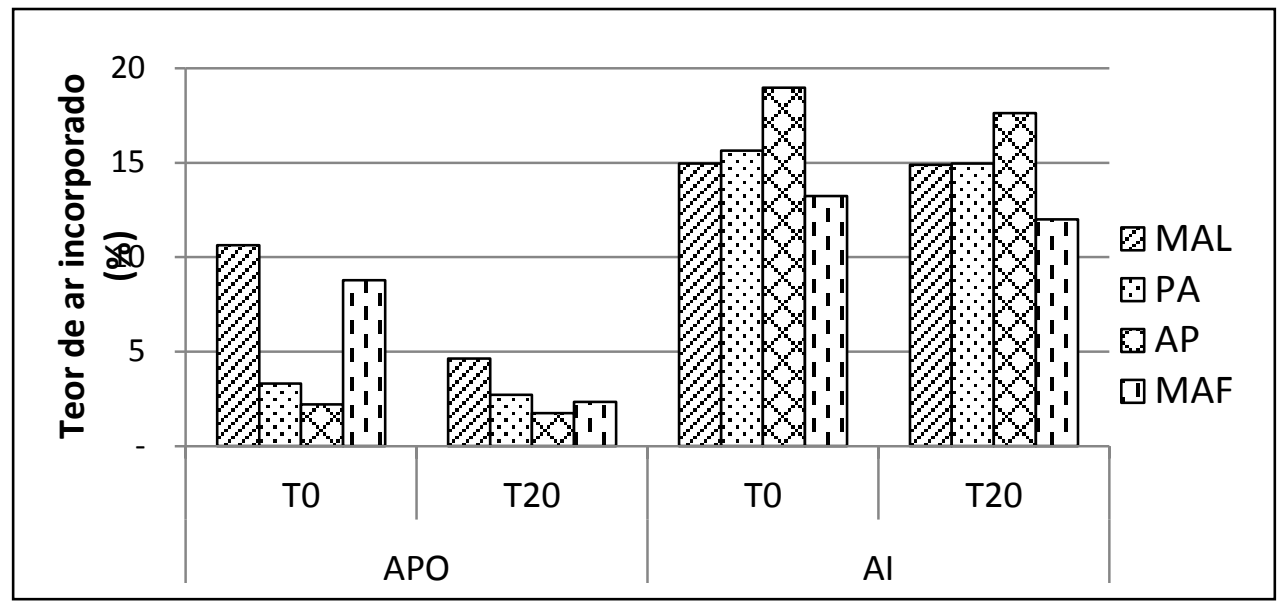

Figura 5: Resultados do teor de ar incorporado nas argamassas.

Ao comparar os procedimentos de mistura, observa-se que para a argamassa industrializada a mistura mecânica AP apresentou menor densidade e maior teor ar (Figuras 3 e 4), enquanto que as misturas MAL e PA apresentaram resultados similares. Segundo ROMANO et al. [27], quando as argamassas são misturadas manualmente, dificilmente é atingido o mesmo nível de desaglomeração e o mesmo teor de ar obtido após a mistura mecânica, devido à menor eficiência, o que foi notado principalmente para argamassa industrializada MAF. Além disso, a produtividade do revestimento aplicado é mais baixa. Indo de encontro à afirmação de ROMANO et al. [27], as argamassas APO apresentaram maiores densidades e menores teores de ar para as misturas mecânicas.

\subsection{Análise do ensaio de Squeeze-flow - Argamassa APO}

A seguir, estão apresentados os resultados obtidos no ensaio de Squeeze-flow, sendo a argamassa produzida em obra representada pelas Figuras 6(a) e (b), e a argamassa industrializada pelas Figuras 6(a) e 6(b), respectivamente.

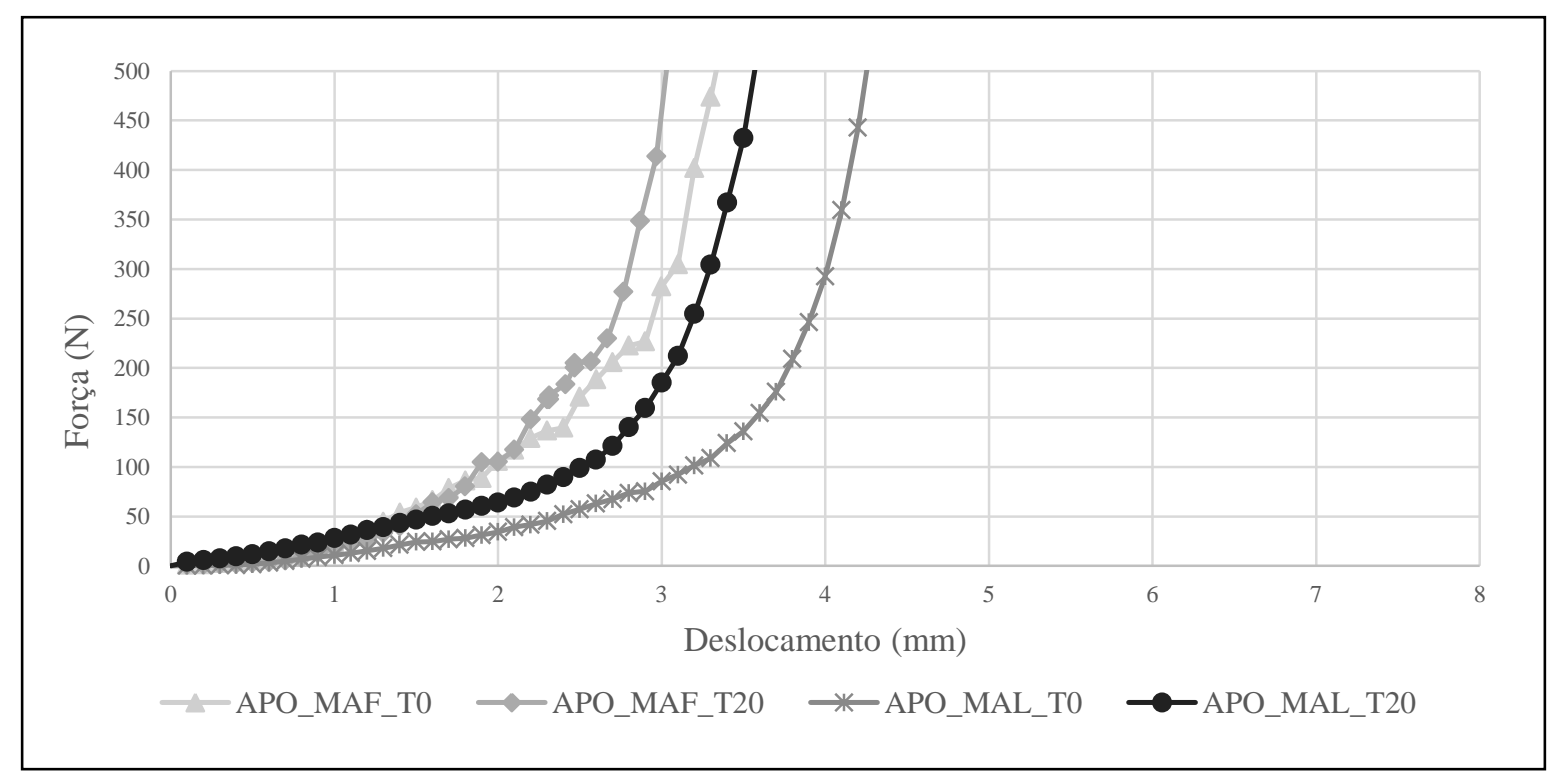

(a) 


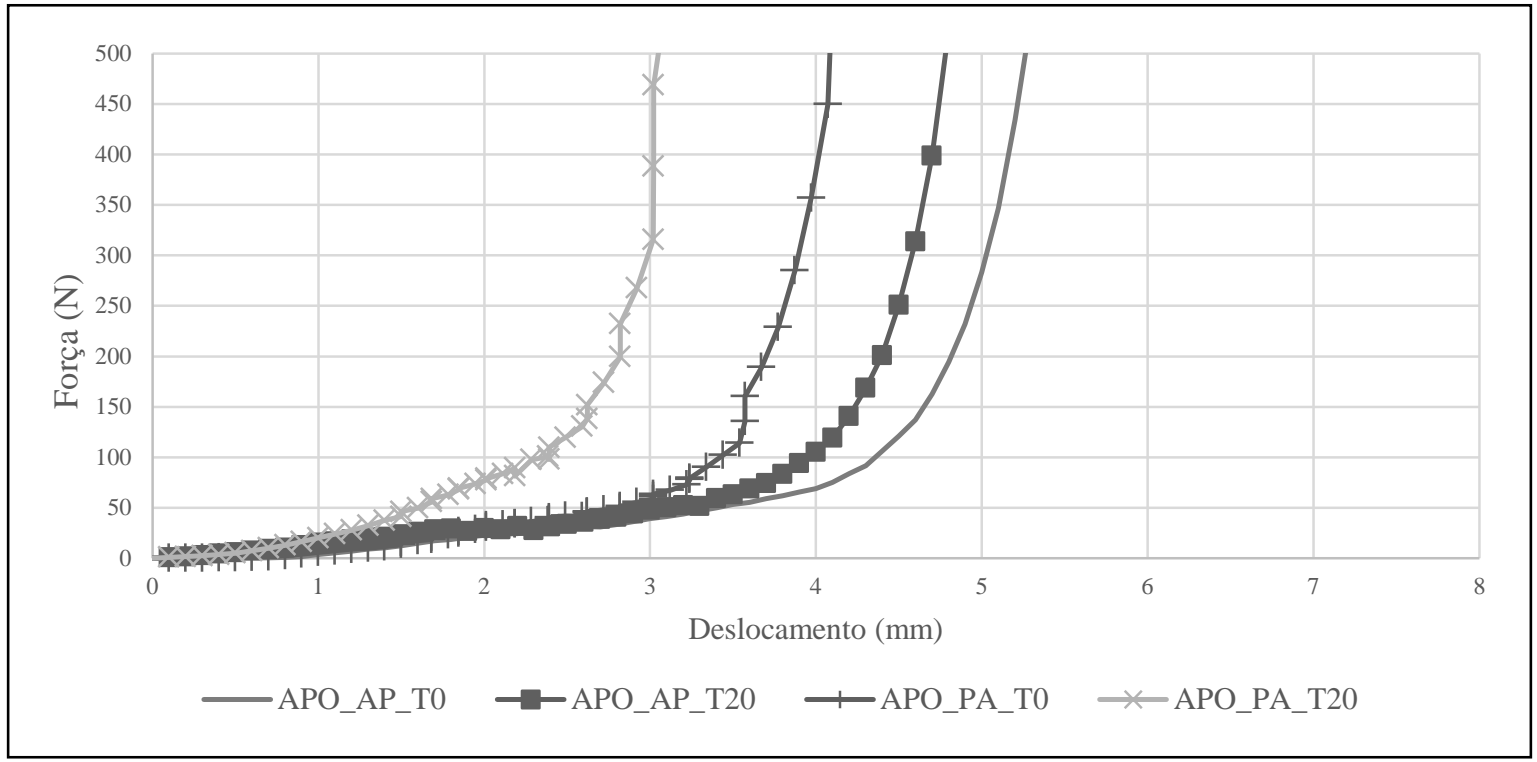

(b)

Figura 6: Resultados do ensaio de Squeeze-flow para a argamassa produzida em obra no tempo zero (T0) e no tempo vinte minutos (T20) para as misturas manuais (a) e mecânicas (b).

A Figura 6(a) contém os resultados da argamassa produzida em obra (APO) pelos métodos de mistura manual MAL e MAF. Desse resultado percebe-se que a argamassa APO no tempo 0 misturada com água livre, foi a que apresentou maior deslocamento antes de apresentar o aumento da carga. Esse resultado é coerente visto que o pedreiro dosou a quantidade de água até que a argamassa apresentasse uma boa aplicabilidade. Ou seja, o trabalhador colocou a quantidade de água que lhe permitiu aplicar a argamassa com menor esforço, gerando uma argamassa com boa deformabilidade à fresco. Com este resultado é possível observar que nem sempre a maior quantidade de água está vinculada à maior trabalhabilidade, tanto que a APO MAL teve menor relação água/ materiais que a mistura APO MAF e, mesmo assim, apresentou melhor trabalhabilidade. Ou seja, o menor teor de ar da MAF, gerado provavelmente pela maior quantidade de água, não contribuiu para um melhor comportamento reológico. Pelo resultado apresentado na Figura 6(a), é percebido que o excedente de água da MAF atrapalhou seu comportamento reológico, enquanto que a MAL, que apresentou menor quantidade de água (e maior teor de ar aprisionado em seu interior) se mostrou mais trabalhável pelo ensaio Squeeze-flow.

Ainda analisando-se a argamassa APO, após 20 min de repouso, notou-se a perda da trabalhabilidade caracterizada pela redução do deslocamento que antecede o aumento da força. Essa perda de trabalhabilidade se dá pela perda de água para o meio externo. Esse efeito ocorre em razão do ar aprisionado presente nas argamassas. Como as argamassas misturadas manualmente apresentaram maior teor de ar aprisionado que as argamassas misturadas mecanicamente, a formação de capilares internos no material provavelmente facilitou o movimento da água de amassamento, consequentemente, facilitando sua perda para o meio externo.

Em contrapartida, a argamassa APO misturada MAF apresenta menor deslocamento na curva do Squeeze-flow. Isso ocorre porque a diferença de teor de água fez com que a MAF tivesse menos ar aprisionado, prejudicando seu comportamento reológico. Portanto, essa seria uma argamassa em que o pedreiro teria maior dificuldade de aplicar. De forma análoga ao método MAL, a argamassa MAF no tempo 0 apresentou maior deslocamento em relação ao tempo de $20 \mathrm{~min}$. Isso ocorreu também devido à perda de água do material para o meio externo.

Na Figura 6(b) apresentam-se os resultados do ensaio do Squeeze-flow para APO agora com os métodos mecanizados AP e PA. Primeiramente, nota-se que a APO T0 misturada com a sequência água no pó, apresenta a curva de maior deslocamento em relação a misturada com a sequência normatizada pó na água. Segundo FRANÇA [28, 29], quanto mais eficiente é o procedimento de mistura na dispersão das partículas e homogeneidade do material maiores serão os deslocamentos alcançados em menores cargas. Portanto, se pode afirmar que o procedimento de mistura AP resulta em um melhor desempenho a trabalhabilidade da argamassa. Ou seja, o tipo de mistura PA não foi capaz de desfazer todos aglomerados de materiais, acarretando no imbricamento precoce e prejudicando a reologia da pasta. 
Ainda mais, ANTUNES et al. [4] explicam que a adição progressiva de água no pó é mais recomendável que a sequência pó na água, adotada pela NBR 13.276 [19], pois apresenta menor variabilidade de comportamento reológico. A viscosidade das argamassas é diminuída tornando necessária uma menor carga para o mesmo nível de deformação. Assim, as argamassas misturadas segundo a sequência água no pó têm maior tendência a apresentar melhor extensão de aderência e, consequentemente, melhor aderência que as misturadas segundo pó na água.

Ressalta-se que para os dois métodos de mistura aos 20 min houve a redução do deslocamento nas curvas. Essa ocorrência também é resultante da perda de água para o meio externo. Ainda mais, para APO misturada por PA houve maior diferença entre as curvas de T0 e T20. Isto, pois esta argamassa apresentou maior teor de ar em relação à misturada por AP, logo, mais capilares que permitiram a perda de água para o meio externo.

Comparando os resultados da Figura 6 (a) e (b), pode-se confirmar que as misturas mecânicas apresentaram argamassas com melhor desempenho reológico que as misturas manuais para argamassas produzidas em obra. Mesmo as misturas mecânicas tendo apresentado maior densidade e menor teor de ar no estado fresco, é possível visualizar que o comportamento reológico dessas foi melhor que das argamassas produzidas com mistura manual, confirmando a teoria de FRANÇA [27, 28].

\subsection{Análise do ensaio de Squeeze-Flow - Argamassa Al}

$\mathrm{Na}$ Figura 7(a) apresentam-se os resultados de Squeeze-flow para a argamassa industrializada misturada manualmente (MAF e MAL). Igualmente visto para a argamassa APO, no tempo 0 a MAL foi a que apresentou maior deformabilidade. Porém, para AI misturada em MAL não houve diferença entre as curvas de T0 e T20. Isso ocorreu provavelmente em razão da composição desta argamassa que para esse tipo de mistura e quantidade de água utilizada não permitiu a perda da trabalhabilidade. Ressalta-se que para a mesma também não houve perda significativa de ar incorporado entre T0 e T20. Em contrapartida, para AI misturada em MAF, houve a perda de trabalhabilidade em relação a MAL, que é resultado provável da diferença do volume de água na mistura. Explica-se que o método de mistura manual não é eficiente para homogeneidade do composto e que, por sua vez, para garantir a trabalhabilidade seria necessário o aumento da quantidade de água que ocorreu com a AI misturada com MAL. Além disso, nota-se significativa diferença entre as curvas de T0 e T20 da MAF, devida à perda de ar na mistura com o tempo, como visto na Figura 5. As bolhas de ar contidas na argamassa fresca atuam como lubrificante da mistura, portanto, a perda de ar deve ter potencializado o embricamento das partículas sólidas aumentando a viscosidade e reduzindo, portanto, a trabalhabilidade da argamassa. 


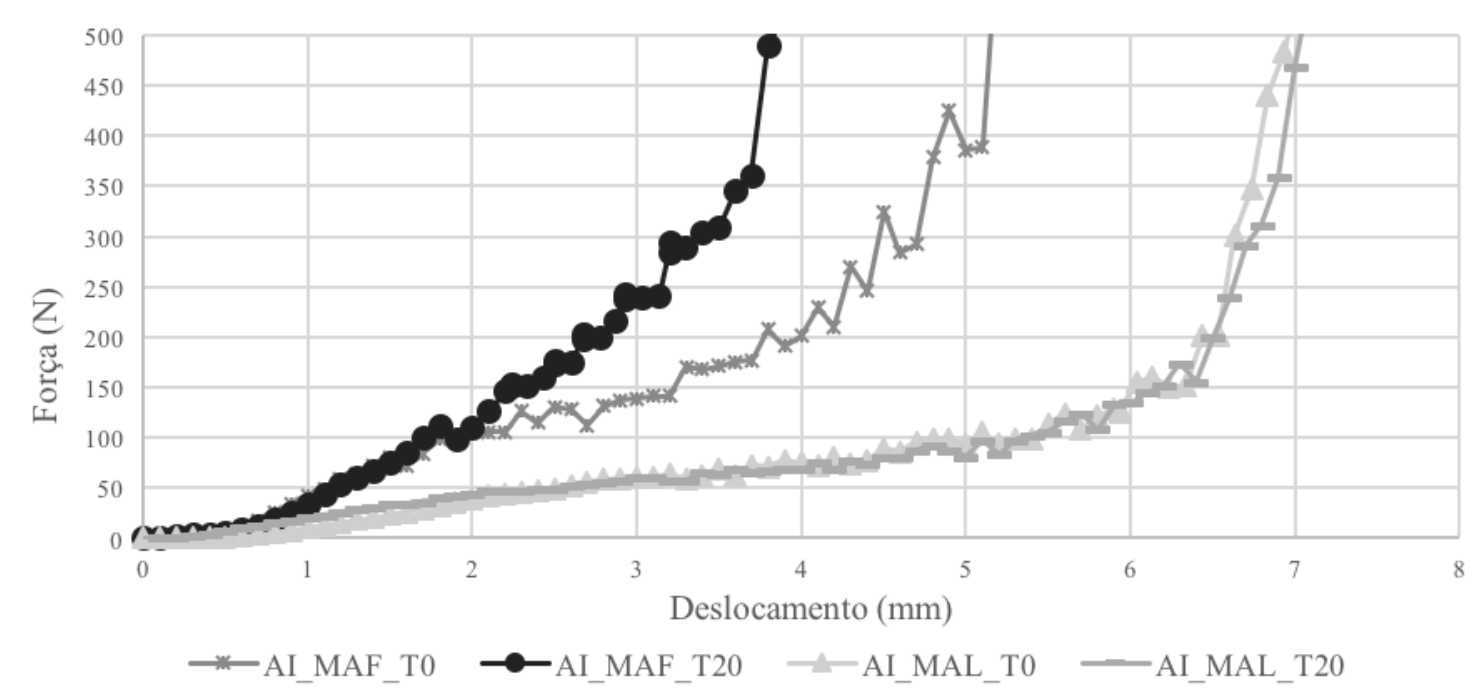

(a)

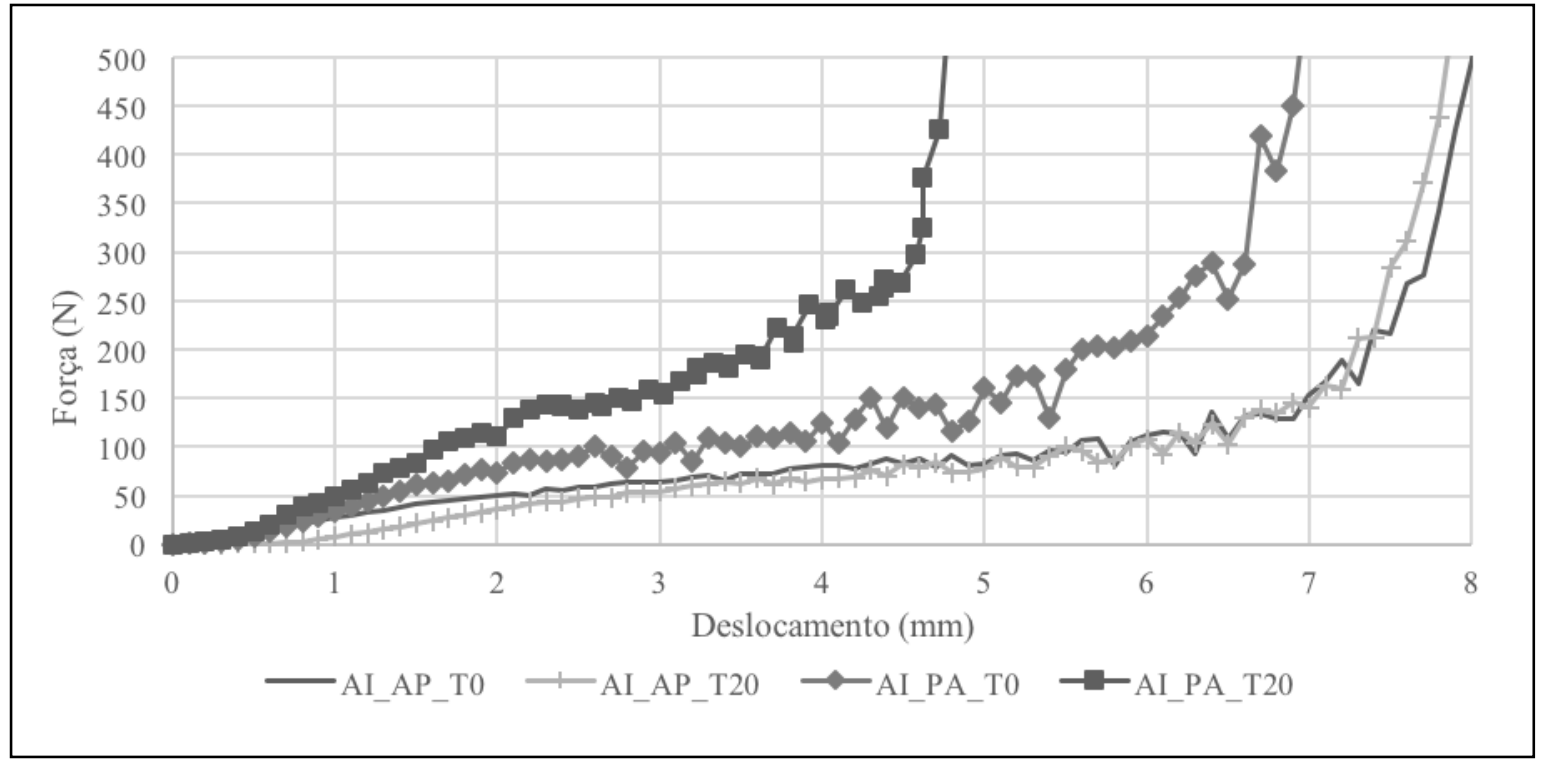

(b)

Figura 7: Resultados do ensaio Squeeze-flow para a argamassa industrializadas no tempo 0 e 20 minutos para as misturas manuais (a) e mecânicas (b).

Na Figura 7(b) estão presentes os resultados do mesmo ensaio para argamassa industrializada, porém misturadas mecanicamente (AP e PO). Do mesmo modo, a lógica do resultado da argamassa APO se manteve, ou seja, a argamassa misturada com AP apresentou melhor resultado que a PA, como era de se esperar pela eficiência de mistura. Por fim, para mistura mecânica no melhor método de mistura não houve diferença entre os resultados nos tempos 0 e $20 \mathrm{~min}$. Isso ocorreu, como já explicado, pelo fato de que a eficiência da mistura pode aumentar a capacidade da argamassa em retenção de água.

Ressalta-se que comparando as argamassas AI e APO, a AI apresentou no geral maior deslocamento nas curvas do ensaio que é característico do material com maior trabalhabilidade. Isso se explica pela composição da AI que pela presença dos aditivos contém bolhas de ar mais estáveis que promovem a viscosidade do sistema produzindo assim uma argamassa mais deformável. Mesmo que a AI contenha agregados miúdos mais lamelares a presença de finos compensa o efeito da forma dos grãos pelo efeito do empacotamento das partículas devido à presença de maior teor de finos promovendo a trabalhabilidade, como visto na literatura. 
Ademais, notou-se que a argamassa APO apresentou segregação visível no ensaio do Squeeze-flow. Isso pode ser explicado pela granulometria dessa argamassa, que por apresentar grãos mais grossos não possui uma matriz com viscosidade insuficiente para manter a mistura coesa. Por fim, as duas argamassas misturadas mecanicamente apresentam maior deformabilidade que é em decorrência da eficiência de mistura.

\section{CONCLUSÕES}

$\mathrm{O}$ procedimento de mistura exerce efeito no comportamento reológico de argamassas de revestimento, além de influenciar também as características de densidade de massa e teor de ar incorporado ou aprisionado. A argamassa produzida em obra (APO) apresentou um desempenho reológico inferior, tanto para as misturas manuais quanto para as mecânicas, isto porque em sua composição não continham aditivos. Essa apresentou, ainda, menor teor de ar e, consequentemente, maior embricamento das partículas sólidas, provocando o aumento da viscosidade. Esse efeito foi agravado pelo tempo em que a mistura permaneceu em repouso, acarretando na diminuição do teor de ar incorporado, prejudicando seu desempenho. Dentre as misturas manuais, a argamassa produzida com água livre (MAL), tanto a produzida em obra ou a industrializada, foi observada uma melhor resposta reológica, que pode ser explicada pela habilidade do operador que, com o conhecimento empírico a respeito da aplicabilidade das argamassas, definiu a quantidade de água. O tipo de mistura que apresentou melhor comportamento reológico foi a composição em que a água foi adicionada no pó (AP), confirmando a teoria de outros pesquisadores que inferiram que este método promove a melhor dispersão dos materiais constituintes. Em contrapartida, a mistura manual água fixa (MAF) demonstrou ser o método menos indicado para as duas formulações de argamassa, isto porque, este procedimento não foi capaz de promover a homogeneidade adequada da mistura, além de disponibilizar uma quantidade de água insuficiente para o preparo da mistura. Para a mistura pó na água (PA), com procedimento previsto na norma NBR 13276 [20], as argamassas apresentaram desempenho inferior ao método água no pó (AP). Isso pode ocorrer pelo fato de que as partículas adicionadas primeiramente na mistura encontram água suficiente para absorver, diferente do cenário encontrado pelas últimas partículas que são adicionadas na mistura. Estas, por sua vez, encontram uma menor quantidade de água disponível para se hidratar e, também, para lubrificar sua superfície. Devido à ausência da água para realizar a lubrificação das partículas, grumos tendem a se formar e a argamassa se torna um material heterogêneo provocado pelas diferentes condições de hidratação e lubrificação das partículas que a constituem, influenciando em sua reologia. Por fim, a argamassa industrializada (AI) apresentou a melhor trabalhabilidade independente do método de mistura adotado. Isto porque, em sua composição, a provável presença de aditivo incorporador de ar proporcionou maior incorporação de ar, contribuindo para a diminuição da viscosidade da mistura. Ademais, para os procedimentos de manual água fixa (MAF) e de pó na água (PA), em que foram identificados desempenhos indesejáveis, a trabalhabilidade da argamassa industrializada (AI) diminuiu com o passar tempo, demonstrando que a inadequada dispersão dos insumos na mistura, pode prejudicar a capacidade da argamassa em manter estáveis suas propriedades ao longo do tempo.

\section{AGRADECIMENTOS}

Os autores agradecem ao Programa de Pós-graduação em Engenharia de Construção Civil (PPGECC) da Universidade Federal do Paraná e, também, à Votorantim que concederam os materiais, os laboratórios e equipamentos necessários para realização desta pesquisa.

\section{BIBLIOGRAFIA}

\section{[1] ABCP. ASSOCIAÇÃO BRASILEIRA DE CIMENTO PORTLAND, Manual de revestimentos de} argamassa. 1. ed. São Paulo, 2002.

[2] SANTOS, L.D., "Sistema de Revestimento com argamassa industrializada", Revista Pensar Engenharia, v.2, n.2, Jul./2014.

[3] YANG, M., JENNINGS, H. M. "Influences of mixing methods on the microstructure and rheological behavior of cement paste", Advanced Cement Based Materials, v.2, pp.70-78, 1995.

[4] ANTUNES, R. P. N. Influência da reologia e da energia de impacto na resistência de aderência de revestimentos de argamassa, Tese D.Sc., Escola Politécnica da USP, São Paulo, SP, Brasil, 2005.

[5] ASSOCIAÇÃO BRASILEIRA DE NORMAS TÉCNICAS. NBR 7200 - Execução de revestimentos de paredes e tetos de argamassas inorgânicas - Procedimento. Rio de Janeiro, 1998.

[6] ROMANO, R. C. O, SCHREURS, H., SILVA, F.B., et al., "Impacto do tipo de misturador e do tempo de mistura nas propriedades de argamassas industrializadas", Revista Ambiente Construído, v.9, n.4, pp. 109118, 2009. 
[7] FERRARIS, C. F., LARRAD, F. Testing and modeling of fresh concrete rheology - NIST IR6094. National Institute of Standards and Technology, 1998.

[8] FERRARIS, C. F. "Measurement of rheological properties of high performance concrete: state of the art report", Journal of Research of the National Institute of Standards and Technology., v. 104, n. 5, 1999. pp 461-478.

[9] PILEGGI, R. G. Ferramentas para o estudo e desenvolvimento de concretos refratários. Tese de D.Sc., Universidade Federal de São Carlos, 2001.

[10] FERRARIS, C. F., BROWER, L. E. Comparison of concrete rheometers: International tests at MB (Cleveland OH, USA) in Mtyay, 2003 - NISTIR 7154. National Institute of Standards and Technology, September, 2004.

[11] ASSOCIAÇÃO BRASILEIRA DE NORMAS TÉCNICAS. NBR 15.839 - Argamassa de assentamento e revestimento de paredes e tetos - Caracterização pelo método Squeeze-flow. Rio de Janeiro, 2010.

[12] PILEGGI, R.G., CINCOTTO, M.A., JOHN, V.M. Aspectos Fundamentais sobre a Natureza Reológica das Argamassas e Análise Crítica das Técnicas de Caracterização do Comportamento Reológico no Estado Fresco. São Paulo, EPUSP, 2004.

[13] CARDOSO, F., PILEGGI, R. G., JOHN, V. M. "Caracterização de argamassas através de reometria por Squeeze-flow". Simpósio Brasileiro de Tecnologia das Argamassas, VI, In: Anais, ANTAC, Camboriú, 2005.

[14] KOLENDA F., RETANA, P., RACINEUX, G., et al., "Identification of rheological parameters by the squeezing test", Powder Technology, v. 130, 2003, p. 56-62.

[15] ÖZKAN, N., OYSU, C., BRISCOE, B. J., et al., "Rheological Analysis of Ceramic Pastes", Journal of the European Ceramic Society, v. 19, 1999, p. 2883-2891.

[16] SMYRNAIOS, D. N., TSAMOPOULOS, J. A. "Squeeze-flow of Bingham plastics", Journal of NonNewtonian Fluid Mechanics,v. 100, pp 165-190, 2001.

[17] CARNEIRO, A. M. P., CINCOTTO, M. A. Dosagem de argamassas através de curvas granulométricas. Boletim Técnico da Escola Politécnica da USP, São Paulo, 1999.

[18] CASTRO, A.L., PANDOLFELli, V.C. "Revisão: Conceitos de dispersão e empacotamento de partículas para a produção de concretos especiais aplicados na construção civil”, Cerâmica, n. 55, pp. 18-32, 2009.

[19] ROMANO, R. C. O. Incorporação de ar em materiais cimentícios aplicados em construção civil. Tese de doutorado em Engenharia Civil. Escola Politécnica da Universidade de São Paulo: São Paulo, 2013.

[20] ASSOCIAÇÃO BRASILEIRA DE NORMAS TÉCNICAS. NBR 7.215 - Cimento Portland Determinação da resistência à compressão. Rio de Janeiro, 1997.

[21] ASSOCIAÇÃO BRASILEIRA DE NORMAS TÉCNICAS. NBR 13.276 - Argamassa para assentamento e revestimento de paredes e tetos - Preparo da mistura e determinação do índice de consistência. Rio de Janeiro, 2005.

[22] ASSOCIAÇÃO BRASILEIRA DE NORMAS TÉCNICAS. NBR 13.278 - Argamassa para assentamento e revestimento de paredes e tetos - Determinação da densidade de massa e do teor de ar incorporado. Rio de Janeiro, 2005.

[23] SILVA, "Avaliação do comportamento da argamassa no estado fresco através dos métodos de mesa de consistência, dropping ball e Squeeze-flow", In: VI Simpósio Brasileiro de Tecnologia de Argamassas, 106120, Florianópolis, SC, Brasil, 2005.

[24] SEABRA, M. P., PAIVA, H., LABRINCHA, J.A., et al., "Admixtures effect on fresh state properties of aerial lime based mortars", Construction and Building Materials, v. 23, pp. 1147-1153, Feb. 2009.

[25] MATANA, A. J., MEDEIROS, M. H. F., SILVA, N. G., et al., "Análise hierárquica para escolha entre agregado natural e areia de britagem de rocha para confecção de argamassas de revestimentos", Revista Ambiente Construído, v. 12, n.4, pp. 63-79, 2012.

[26] ASSOCIAÇÃO BRASILEIRA DE NORMAS TÉCNICAS. NBR 13.281 - Argamassa para assentamento e revestimento de paredes e tetos - Requisitos. Rio de Janeiro, 2005.

[27] ROMANO, R. C. O., SCHREURS., H., SILVA, F.B., et al. Efeito do Procedimento de Mistura nas Características de Argamassas de Revestimento Industrializadas, In: Congresso Português de Argamassas de Construção, Lisboa, 2010.

[28] FRANÇA, M. S. "Comportamento de mistura de sistemas cimentícios multifásicos reativos", Dissertação de M.Sc., Escola Politécnica da USP, São Paulo, SP, Brasil, 2013. 
[29] FRANÇA, M. S., CARDOSO, F. A., PILEGGI, R. G. "Influência do procedimento de mistura em laboratório nas propriedades de argamassas", Revista Ambiente Construído, v. 13, n. 2, pp. 111-123, 2013. 